\title{
A wide variation of the quality of colonoscopy reporting system in the real clinical practice in southeastern area of Korea
}

\author{
Jung Min Lee ${ }^{1 *}$, Yu Jin Kang ${ }^{1 *}$, Eun Soo Kim², Yoo Jin Lee ${ }^{1}$, Kyung Sik Park ${ }^{1}$, Kwang Bum Cho ${ }^{1}$, \\ Seong Woo Jeon ${ }^{2}$, Min Kyu Jung ${ }^{2}$, Hyun Seok Lee ${ }^{2}$, Eun Young Kim³, Jin Tae Jung ${ }^{3}$, Byung Ik Jang ${ }^{4}$, \\ Kyeong Ok Kim ${ }^{4}$, Yun Jin Chung, ${ }^{5}$ Chang Hun Yang ${ }^{6}$; Daegu-Gyeongbuk Gastrointestinal Study Group (DGSG) \\ ${ }^{1}$ Division of Gastroenterology, Department of Internal Medicine, Keimyung University School of Medicine, Daegu, ${ }^{2}$ Division of Gastroenterology \\ and Hepatology, Department of Internal Medicine, Kyungpook National University School of Medicine, Daegu, ${ }^{3}$ Division of Gastroenterology \\ and Hepatology, Department of Internal Medicine, Catholic University of Daegu School of Medicine, Daegu, ${ }^{4}$ Division of Gastroenterology and \\ Hepatology, Department of Internal Medicine, Yeungnam University College of Medicine, Daegu, ${ }^{5}$ Division of Gastroenterology, Department \\ of Internal Medicine, Fatima Hospital of Daegu, Daegu, ${ }^{6}$ Division of Gastroenterology and Hepatology, Department of Internal Medicine, \\ Dongguk University School of Medicine, Gyeongju, Korea
}

Background/Aims: Establishment of a colonoscopy reporting system is a prerequisite to determining and improving quality. This study aimed to investigate colonoscopists' opinions and the actual situation of a colonoscopy reporting system in a clinical practice in southeastern area of Korea and to assess the factors predictive of an inadequate reporting system. Methods: Physicians who performed colonoscopies in the Daegu-Gyeongbuk province of Korea and were registered with the Korean Society of Gastrointestinal Endoscopy (KSGE) were interviewed via mail about colonoscopy reporting systems using a standardized questionnaire. Results: Of 181 endoscopists invited to participate, 125 responded to the questionnaires (response rate, $69 \%)$. Most responders were internists $(105 / 125,84 \%)$ and worked in primary clinics $(88 / 125,70.4 \%)$. Seventy-one specialists (56.8\%) held board certifications for endoscopy from the KSGE. A median of 20 colonoscopies (interquartile range, 10-47) was performed per month. Although $88.8 \%$ of responders agreed that a colonoscopy reporting system is necessary, only $18.4 \%$ (23/125) had achieved the optimal reporting system level recommended by the Quality Assurance Task Group of the National Colorectal Cancer Roundtable. One-third of endoscopists replied that they did not use a reporting document for the main reasons of "too busy" and "inconvenience." Non-endoscopy specialists and primary care centers were independent predictive factors for failure to use a colonoscopy reporting system. Conclusions: The quality of colonoscopy reporting systems varies widely and is considerably suboptimal in actual clinical practice settings in southeastern Korea, indicating considerable room for quality improvements in this field. (Intest Res 2016;14:351-357)

Key Words: Colonoscopy; Report; Survey; Quality

Received October 16, 2015. Revised December 2, 2015.

Accepted December 4, 2015.

Correspondence to Eun Soo Kim, Division of Gastroenterology and

Hepatology, Department of Internal Medicine, Kyungpook National

University School of Medicine, 130 Dongdeok-ro, Jung-gu, Daegu 41944,

Korea. Tel: +82-53-200-5512, Fax:+82-53-200-5879, E-mail: dandy813@

hanmail.net

*These authors contributed equally to this study.

Financial support: None. Conflict of interest: None.

\section{INTRODUCTION}

The demand for colonoscopy, which has been recognized as a pivotal tool in colorectal cancer (CRC) screening, has increased significantly in many developed countries. ${ }^{1,2}$ The importance of colonoscopy is related to the detection and removal of colorectal adenomatous polyps during the procedure, which may prevent the development of CRC and

\footnotetext{
(c) Copyright 2016. Korean Association for the Study of Intestinal Diseases. All rights reserved.

This is an Open Access article distributed under the terms of the Creative Commons Attribution Non-Commercial License (http://creativecommons.org/licenses/by-nc/4.0)

which permits unrestricted non-commercial use, distribution, and reproduction in any medium, provided the original work is properly cited.
} 
ultimately lead to a significant reduction in mortality. ${ }^{3}$ However, many studies have revealed that colonoscopy is not fully effective as a method of protecting the colon from CRC, particularly interval cancer. ${ }^{4-7}$ Interval cancer development has been suggested to correlate with the adenoma detection rate, an indicator of colonoscopy quality that varies among physicians; specifically, endoscopists with lower adenoma detection rates are associated with a higher risk of interval cancer. ${ }^{8,9}$ Therefore, increasing attention has been paid to colonoscopy quality, and specific recommendations of quality indicators have been made to ensure the continuous improvement of colonoscopy quality and effectiveness. ${ }^{10}$

Optimal reporting of colonoscopic procedures should be required in order to measure the performance of colonoscopists and monitor quality indicators in clinical practice. In 2007, a standardized colonoscopy reporting system was developed by the Quality Assurance Task Force of the National Colorectal Cancer Roundtable in an effort to facilitate continuous quality improvements across diverse practices using colonoscopy. ${ }^{11}$ Nevertheless, the level of reporting of these indicators has often been insufficient in daily clinical practice. $^{12-14}$

South Korea implemented the National Cancer Screening Program in 1999 to address the high incidence of cancer; as a result, a tremendous number of colonoscopies were conducted in clinical practice. ${ }^{15}$ Nevertheless, no data have demonstrated the actual situation of colonoscopy reporting systems in daily clinical practices in South Korea, although these data might provide a comprehensive insight into colonoscopy quality in this region.

The present study aimed to assess the quality of colonoscopy reports using a standardized questionnaire administered to a wide range of clinical centers with different expertise levels and workloads located in the Daegu-Gyeongbuk province in southeastern South Korea. The study also evaluated predictive factors of a failure to use colonoscopy reporting systems.

\section{METHODS}

\section{Survey of Questionnaire}

From January to May 2012, a survey of colonoscopy reporting systems was administered to physicians performing colonoscopy at institutions with various care levels (e.g., primary clinical practice to tertiary referral hospitals) in a southeastern province of South Korea. The physicians were registered as members of the Korean Society of Gastroin- testinal Endoscopy (KSGE), and a list of physicians was obtained from the official secretariat of this society. Physicians were categorized in two groups, endoscopy specialists and non-endoscopy specialists, based on KSGE board certification. This certification can be achieved after undergoing a dedicated 12-month endoscopy training session and passing a standard examination, regardless of department. ${ }^{16}$ Sociodemographic data collected from participants included sex, age, care level of hospital where they worked, department (internal medicine, surgery, or family medicine), and number of colonoscopies performed. A standardized questionnaire was sent by mail to a total of 181 physicians. This study was approved by the Ethics Review Committee of the Institutional Review Board of the Keimyung University Dongsan Hospital.

\section{Colonoscopy Reporting System Questionnaire}

The main survey questions were as follows:

(1) Do you believe that a colonoscopy reporting system is necessary?

(2) Do you have an official colonoscopy reporting system in your clinic? (What is the level of your reporting system?)

(3) If you do not have a reporting system, what is the most likely reason?

Regarding the colonoscopy reporting system level, we classified the answers into four categories: optimal, suboptimal, only simple notes, and no report. An "optimal" reporting system incorporated the data elements recommended by the Quality Assurance Task Group of the National Colorectal Cancer Roundtable, including procedure indications, sedation, extent of examination, withdrawal time, bowel preparation, colonoscopic findings (e.g., location, size, and morphology of polyps), and final assessment. "11 "Suboptimal" indicated that the reporting system did not fulfill all of the recommended elements of the aforementioned optimal level system (e.g., merely describing the colonoscopic findings). "Simple notes" were defined as a lack of report documentation, although notes were recorded in the patient's medical records or lesions were marked on images. "No report" indicated to a lack of report documentation or images of colonoscopic procedures. The latter two answers (simple notes and no report) were regarded as failure to use a colonoscopy reporting system.

\section{Statistical Analysis}

Data are reported as numbers of cases (\%) or as medians 
with interquartile ranges. For comparisons of categorical variables, Fisher exact test and the chi-square test were used. Differences in continuous variables were assessed with the Mann-Whitney test. Bonferroni's correction was performed when there were multiple comparisons. To determine the independent predictive factors for failure to use a colonoscopy reporting system, a logistic regression analysis was performed using variables for which statistically significant associations were identified in a univariate analysis. A twotailed $P$-value $<0.05$ was considered statistically significant. SPSS software version 14.0 (SPSS Inc., Chicago, IL, USA) was used for the statistical analysis.

\section{RESULTS}

\section{Participating Physicians}

Among the 181 physicians invited to participate in the survey, 125 returned their responses (response rate, $69 \%$ ). Most of the respondents were men $(111,88.8 \%)$ aged 40 to 49 years $(69,55.2 \%)$. Internal medicine $(105,84 \%)$ was the most common department, followed by surgery $(17,13.6 \%)$ and family medicine $(3,2.4 \%)$. The majority of physicians worked in primary clinics $(88,70.4 \%)$ and secondary care hospitals $(32,25.6 \%)$. Only five respondents $(4 \%)$ were employed at tertiary referral hospitals. Seventy-one physicians (56.8\%) had achieved board-certified endoscopy accreditation by the KSGE and were considered endoscopy specialists. The median number of colonoscopy cases per month was 20, with an interquartile range of 10 to 47 . These demographic characteristics of the physicians are described in Table 1.

Regarding the first question, "Do you believe that a colonoscopy reporting system is necessary?," most physicians, regardless of department, hospital level, and endoscopy specialist certification status, agreed that such a system is necessary. Interestingly, however, significant differences in the responses to the second question, "Do you have an official colonoscopy reporting system in your clinic?" were observed among the physicians. Internists were significantly more likely to have implemented an optimal-level reporting system, compared with surgeons or family physicians ( $21 \%$ vs. $5.9 \%$ vs. $0 \%$, $P=0.015$ ), and physicians working at tertiary hospitals used an optimal-level reporting system significantly more frequently than those working in second hospitals or primary clinics ( $80 \%$ vs. $34.4 \%$ vs. $9.1 \%, P<0.001$ ). Moreover, most responders working in primary clinics, who accounted for the largest proportion of participating physicians in the study, replied that the reporting systems used in their practices were either of the suboptimal (47.7\%) or only simple notes level (39.8\%). Endoscopic specialists with board certification were more likely than non-specialists to use an optimal-level reporting system $(26.8 \%$ vs. $7.4 \%, P<0.001)$. Overall, approximately $90 \%$ of the physicians replied that they believed that colonoscopy reporting is necessary, whereas only $18 \%$ of the participants used an optimal-level reporting system. Furthermore, $30 \%$ of the physicians did not even use a colonoscopic reporting system in their clinics; instead, they took simple notes on medical records or images, or made no report (Table 2).

\section{Reasons for Not Using a Colonoscopy Reporting System}

The next question was only asked of physicians who did not use a colonoscopy reporting system (i.e., simple notes or no report): what is the most likely reason for not using a reporting system? The most common reasons were "inconvenience" (38\%) and being "too busy" (38\%) to use a reporting system, followed by "lack of confidence" (13\%) and "lack of knowledge” (3\%) (Fig. 1).

Table 1. Demographic Characteristics of the Participating Physicians

\begin{tabular}{lc}
\hline \multicolumn{1}{c}{ Characteristic } & Value $(\mathbf{n = 1 2 5 )}$ \\
\hline Age $(\mathrm{yr})$ & $28(22.4)$ \\
$31-40$ & $69(55.2)$ \\
$41-50$ & $22(17.6)$ \\
$51-60$ & $6(4.8)$ \\
$\geq 61$ & \\
Sex & $111(88.8)$ \\
Male & $14(11.2)$ \\
Female & \\
Department & $105(84.0)$ \\
Internist & $17(13.6)$ \\
Surgeon & $3(2.4)$ \\
Family physician & \\
Hospital & $88(70.4)$ \\
Primary & $32(25.6)$ \\
Secondary & $5(4.0)$ \\
Tertiary & $71(56.8)$ \\
Endoscopy specialist ${ }^{a}$ & $20(10-47)$ \\
Colonoscopy cases per month & \\
\hline
\end{tabular}

Values are presented as number (\%) or median (interquartile range).

${ }^{a}$ Specialist refers to colonoscopists with board certification from the Korean Society of Gastrointestinal Endoscopy. 


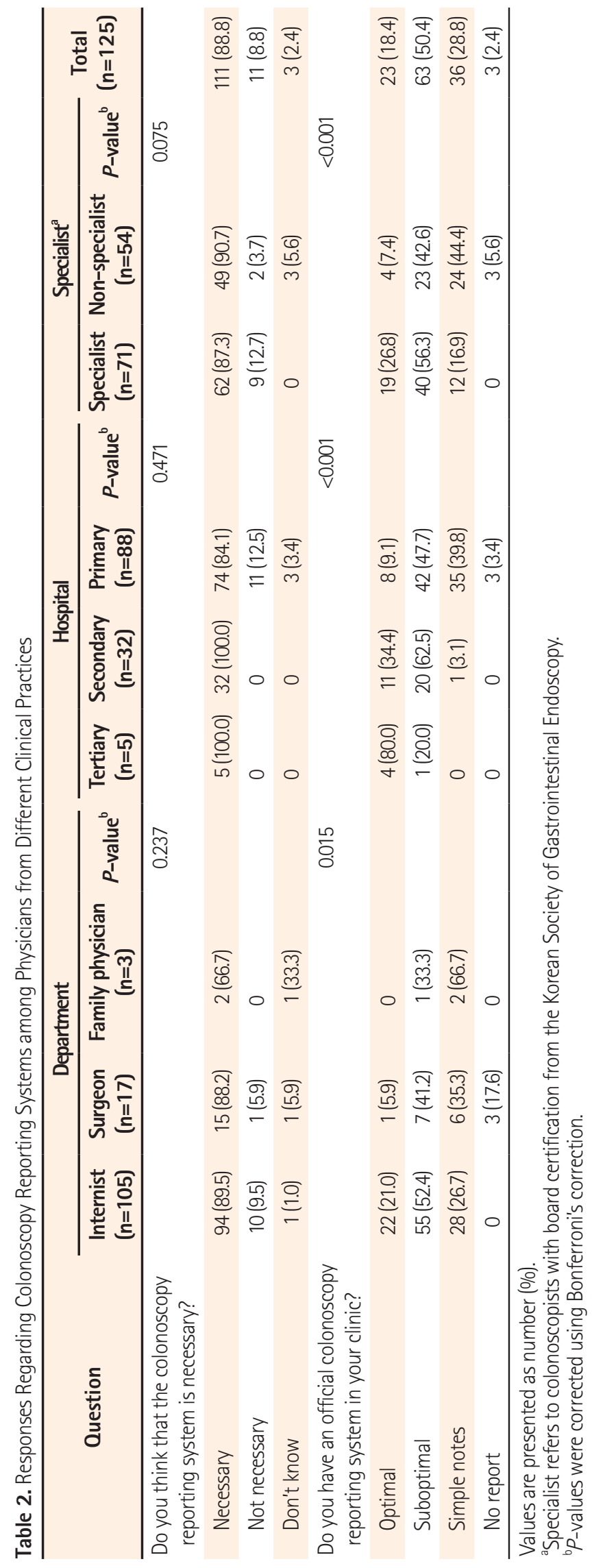

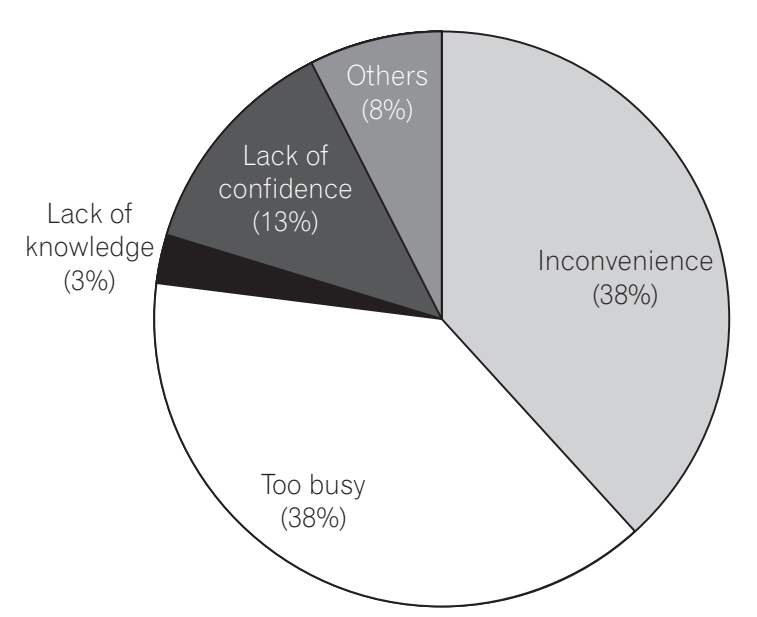

Fig. 1. Various reasons for failure to use a colonoscopy reporting system.

Table 3. Univariate Analysis of Predictive Factors for Failure to Use a Colonoscopy Reporting System

\begin{tabular}{|c|c|c|c|}
\hline Variable & $\begin{array}{l}\text { Not using a } \\
\text { reporting } \\
\text { system } \\
(n=39)\end{array}$ & $\begin{array}{l}\text { Using a } \\
\text { reporting } \\
\text { system } \\
(n=86)\end{array}$ & $P$-value \\
\hline Sex & & & 0.546 \\
\hline Male & $36(92.3)$ & 75 (87.2) & \\
\hline Female & $3(7.7)$ & $11(12.8)$ & \\
\hline Age $>50 \mathrm{yr}$ & $15(38.5)$ & $13(15.1)$ & 0.005 \\
\hline Non-internists & $11(28.2)$ & $9(10.5)$ & 0.018 \\
\hline Primary care center & $38(97.4)$ & $50(58.1)$ & $<0.001$ \\
\hline Non-endoscopy specialist & $27(69.2)$ & $27(31.4)$ & $<0.001$ \\
\hline Colonoscopy cases per month & $10(5-20)$ & $30(15-53)$ & $<0.001$ \\
\hline
\end{tabular}

\section{Predictive Factors for Not Using a Colonoscopy Reporting System}

A univariate analysis identified an age $>50$ years, noninternist status (surgeons and family physicians), working at a primary care center, non-endoscopy specialist status, and a low number of colonoscopies per month were significantly associated with failure to use a reporting system (Table 3). Of these factors, working at a primary care center (OR, 19.99; 95\% CI, 2.54-157.56; $P=0.004)$ and non-endoscopy specialist status (OR, 2.99; 95\% CI, 1.08-8.24; $P=0.034$ ) were identified as independent predictive factors for failure to use a reporting system in a multivariate analysis (Table 4). 
Table 4. Multivariate Analysis of Predictive Factors for Failure to Use a Colonoscopy Reporting System

\begin{tabular}{lrlc}
\hline \multicolumn{1}{c}{ Variable } & OR & \multicolumn{1}{c}{ 95\% Cl } & $\boldsymbol{P}$-value \\
\hline Age $>50$ yr & 2.42 & $0.79-7.42$ & 0.123 \\
Non-internist & 1.14 & $0.33-3.94$ & 0.838 \\
Primary care center & 19.99 & $2.54-157.56$ & 0.004 \\
Non-endoscopy specialist & 2.99 & $1.08-8.24$ & 0.034 \\
Colonoscopy cases per month & 0.99 & $0.97-1.01$ & 0.213 \\
\hline
\end{tabular}

\section{DISCUSSION}

The results of the present questionnaire-based study revealed broad variability in the quality of colonoscopy reporting systems among physicians, thus reflecting the real-world experience in a southeastern area of South Korea. We found that the reporting system quality was considerably inadequate, although this depended on the department, hospital care level, and endoscopy specialist accreditation status. One-third of the responders did not use a colonoscopy reporting system for various reasons, and a non-endoscopy specialist status and working in a primary clinic were factors significantly associated with this outcome.

In general, endoscopy reports are considered fundamental elements of medical records because they serve as an important means of communicating information related to endoscopic findings, procedures, and recommendations among physicians. In addition, colonoscopy reporting has received significantly increased attention, as a recent body of evidence emphasized the significance of colonoscopy quality issues with regard to CRC screening. ${ }^{10}$ Many colonoscopy quality indicators, including bowel preparation, withdrawal time, and adenoma detection rate, are only meaningful when they are adequately recorded. Colonoscopy quality cannot not be determined without the accurate and complete reporting of these colonoscopy parameters. In this context, the results of the present study raised profound concerns about the quality of colonoscopies performed in this region.

Although the exact impact of incomplete colonoscopy reporting is not clear, we can surmise several plausible consequences. For instance, it is impossible to recommend an optimal follow-up schedule of procedures without knowing the bowel preparation status. ${ }^{13}$

Detailed information about polyps is essential in clinical practice, particularly with regard to communication between referring physicians and physicians at referral centers; for example, polyp size and morphology data could greatly facilitate risk assessments of the malignant potential of tumors and decisions regarding optimal treatment approaches. ${ }^{17,18}$ Without this information, unnecessary repeat colonoscopies may be performed, with consequent increased costs and greater procedural risks. Most of all, the greatest concern associated with insufficient colonoscopy documentation might be the development of interval cancer, although no evidence has suggested that poor colonoscopy reporting is directly related to the risk of interval cancer. Further studies of the precise impacts of insufficient colonoscopy reporting on clinical outcomes are needed. At the very least, we can measure and improve colonoscopists' performances to determine whether the reporting is good.

One notable finding of our study was the existence of different grades of reporting quality according to the hospital, department, procedure number, and endoscopy specialist accreditation. Furthermore, we found that working at a primary care center and a non-endoscopy specialist status were independent predictors of failure to use a colonoscopy reporting system. This result was in agreement with the findings of a previous study, in which gastroenterologists were found to achieve better reporting and performance quality, compared with non-gastroenterologists. ${ }^{19}$ Indeed, evidence has shown an association between colonoscopy performed by non-gastroenterologists and an increased risk of interval cancer. ${ }^{20-22}$ Although it is difficult to directly compare studies from different countries because of variations in medical training systems, South Korean endoscopy specialists might correspond to gastroenterologists in previous studies, as both certifications require a certain period of specified training and examination to ensure good-quality endoscopic examinations. ${ }^{16,21}$ Another South Korean study also reported that the achievement of endoscopy specialty qualification by the KSGE was associated with high-quality endoscopy performance. $^{16}$

As indicated in our study, which identified "inconvenience" or being "too busy" as the main reasons for not reporting colonoscopy parameters, the main obstacle to complete colonoscopy reporting might be the physician's perception of colonoscopy reporting as a slow, laborious task. For clinical and quality purposes, additional time and effort are needed when inputting data into colonoscopy reports. ${ }^{23}$ For instance, although the KSGE has begun to provide and encourage the use of a standardized colonoscopy report form on its website, ${ }^{24}$ this form might not be useful unless it is incorporated into the medical records systems of individual centers. One potential solution for improved compliance would be a computerized endoscopy reporting system with a structured input matrix, instead of a handwritten or free- 
text dictation system. ${ }^{25}$

In the same context, we noticed a significant discrepancy between the perceived necessity of colonoscopy reporting and implementation of this necessity in actual clinical practices. Although most responders understood that colonoscopy reporting is essential, they ignored this knowledge in their routine clinical practices. Therefore, efforts should be undertaken to develop and provide computerized colonoscopy reporting systems that do not require dual data entry and can be easily utilized in a primary clinical setting.

The strength of this study was its evaluation of the situation of real-life colonoscopy documentation across a broad spectrum of physicians; accordingly, our results offer a comprehensive insight into colonoscopy quality in this region. Because most studies of colonoscopy quality have been conducted in non-daily clinical settings such as screening programs and research-based academic hospitals, very limited data on primary care centers are available. To our knowledge, this study was the first to evaluate colonoscopists' opinions and the actual situation of colonoscopy reporting systems in daily clinical practices in Asia.

However, this study had some limitations. First, we did not evaluate specific parameters, such as the cecal intubation rate, withdrawal time, and adenoma detection rate, which are known surrogate markers of colonoscopy quality. Therefore, the performance quality achieved by individual colonoscopists remains unknown. Second, because this study featured a cross-sectional design, we could not evaluate changes in the quality of reporting over time or observe the effects of interventions on the quality of reporting in this population.

In conclusion, this questionnaire-based study observed a wide variation in the quality of colonoscopy reporting systems that depended on the hospital care level and endoscopist's expertise, indicating much room for improvement in colonoscopy quality control. In particular, there is an urgent need for the development of endoscopist-friendly, computerized colonoscopy reporting systems that do not require dual data entry in daily clinical practices in South Korea. Further study is needed to confirm the precise impact of inadequate-quality colonoscopy reporting systems on clinical outcomes.

\section{REFERENCES}

1. Lin OS, Kozarek RA, Cha JM. Impact of sigmoidoscopy and colonoscopy on colorectal cancer incidence and mortality: an evidence-based review of published prospective and retrospective studies. Intest Res 2014;12:268-274.

2. Parente F, Marino B, Ardizzoia A, et al. Impact of a populationbased colorectal cancer screening program on local health services demand in Italy: a 7-year survey in a northern province. Am J Gastroenterol 2011;106:1986-1993.

3. Zauber AG, Winawer SJ, O'Brien MJ, et al. Colonoscopic polypectomy and long-term prevention of colorectal-cancer deaths. N Engl J Med 2012;366:687-696.

4. Singh H, Nugent Z, Demers AA, Kliewer EV, Mahmud SM, Bernstein CN. The reduction in colorectal cancer mortality after colonoscopy varies by site of the cancer. Gastroenterology 2010;139:1128-1137.

5. Bressler B, Paszat LF, Vinden C, Li C, He J, Rabeneck L. Colonoscopic miss rates for right-sided colon cancer: a populationbased analysis. Gastroenterology 2004;127:452-456.

6. Baxter NN, Goldwasser MA, Paszat LF, Saskin R, Urbach DR, Rabeneck L. Association of colonoscopy and death from colorectal cancer. Ann Intern Med 2009;150:1-8.

7. Brenner H, Hoffmeister M, Arndt V, Stegmaier C, Altenhofen L, Haug U. Protection from right- and left-sided colorectal neoplasms after colonoscopy: population-based study. J Natl Cancer Inst 2010;102:89-95.

8. Barclay RL, Vicari JJ, Doughty AS, Johanson JF, Greenlaw RL. Colonoscopic withdrawal times and adenoma detection during screening colonoscopy. N Engl J Med 2006;355:2533-2541.

9. Kaminski MF, Regula J, Kraszewska E, et al. Quality indicators for colonoscopy and the risk of interval cancer. N Engl J Med 2010;362:1795-1803.

10. Rex DK, Petrini JL, Baron TH, et al. Quality indicators for colonoscopy. Am J Gastroenterol 2006;101:873-885.

11. Lieberman D, Nadel M, Smith RA, et al. Standardized colonoscopy reporting and data system: report of the Quality Assurance Task Group of the National Colorectal Cancer Roundtable. Gastrointest Endosc 2007;65:757-766.

12. Lieberman DA, Faigel DO, Logan JR, et al. Assessment of the quality of colonoscopy reports: results from a multicenter consortium. Gastrointest Endosc 2009;69(3 Pt 2):645-653.

13. Robertson DJ, Lawrence LB, Shaheen NJ, et al. Quality of colonoscopy reporting: a process of care study. Am J Gastroenterol 2002;97:2651-2656. 
14. Li J, Nadel MR, Poppell CF, Dwyer DM, Lieberman DA, Steinberger EK. Quality assessment of colonoscopy reporting: results from a statewide cancer screening program. Diagn Ther Endosc 2010;2010. pii: 419796.

15. Cha JM. Quality improvement of gastrointestinal endoscopy in Korea: past, present, and future. Korean J Gastroenterol 2014;64:320-332.

16. Cha JM, Han DS, Lee HL, et al. Endoscopist specialty is associated with high-quality endoscopy in Korea. Yonsei Med J 2012;53:310-317.

17. Martînez ME, Sampliner R, Marshall JR, Bhattacharyya AK, Reid ME, Alberts DS. Adenoma characteristics as risk factors for recurrence of advanced adenomas. Gastroenterology 2001;120:1077-1083.

18. Lee YJ, Kim ES, Park KS, et al. Inter-observer agreement in the endoscopic classification of colorectal laterally spreading tumors: a multicenter study between experts and trainees. Dig Dis Sci 2014;59:2550-2556.

19. de Jonge V, Sint Nicolaas J, Cahen DL, et al. Quality evaluation of colonoscopy reporting and colonoscopy performance in daily clinical practice. Gastrointest Endosc 2012;75:98-106.
20. Bressler B, Paszat LF, Chen Z, Rothwell DM, Vinden C, Rabeneck L. Rates of new or missed colorectal cancers after colonoscopy and their risk factors: a population-based analysis. Gastroenterology 2007;132:96-102.

21. Rabeneck L, Paszat LF, Saskin R. Endoscopist specialty is associated with incident colorectal cancer after a negative colonoscopy. Clin Gastroenterol Hepatol 2010;8:275-279.

22. Singh H, Nugent Z, Demers AA, Bernstein CN. Rate and predictors of early/missed colorectal cancers after colonoscopy in Manitoba: a population-based study. Am J Gastroenterol 2010;105:2588-2596.

23. Aabakken L. Quality reporting: finally achievable? Endoscopy 2014;46:188-189.

24. Colonoscopy report. Korean Society of Gastrointestinal Endoscopy. http://gie.or.kr/bbs/?code=file. Accessed Jul 14, 2015.

25. van Doorn SC, van Vliet J, Fockens P, Dekker E. A novel colonoscopy reporting system enabling quality assurance. Endoscopy 2014;46:181-187. 